\title{
ALCANCE
}

\section{A INOVAÇÃO COMO IMPULSO À INVERSÃO DA CONDIÇÃO DE ATRASO: UMA REALIDADE PARA O CASO BRASILEIRO?}

INNOVATION AS AN IMPULSE TO INVERSION OF THE DELAY CONDITION: A REALITY FOR THE BRAZILIAN CASE?

LA INNOVACIÓN COMO IMPULSO A LA INVERSIÓN DE LA CONDICIÓN DE RETRASO: ¿UNA REALIDAD PARA EL CASO BRASILEÑO?

\author{
NAYARA GONÇALVES LAURIANO \\ Mestranda \\ Universidade Federal de Viçosa - Brasil \\ ORCID: 0000-0002-0992-9882 \\ nayaralauriano@gmail.com \\ Submetido em: 08/03/2019 \\ Aprovado em: 06/09/2019
}

Doi: 10.14210.alcance.v26n3(set/dez).p348-362

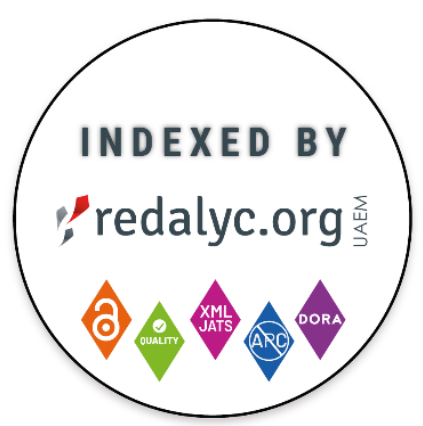

LCENÇA CC BY:

Artigo distribuído sob os termos

Creative Commons,

permite uso e

distribuição irrestrita

em qualquer meio

desde que o autor

credite a fonte

original.

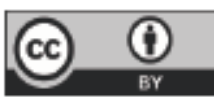




\title{
RESUMO
}

A inovação tem sido estratégica para impulsionar o processo de desenvolvimento. Consciente disso, o Brasil vem formulando diretrizes para impulsionar sua capacidade de desenvolver tecnologia e inovar, porém os resultados acumulados ao longo dos anos são ainda modestos. 0 objetivo deste artigo é permitir uma exposição lógica e discursiva acerca da suficiência da inovação como alavanca para o desenvolvimento das economias subdesenvolvidas na conjuntura atual. Com isso, o trabalho se organizou no formato de ensaio teórico, dialogando com a literatura que articula a inovação como elemento para o desenvolvimento e com dados que exploram a realidade brasileira. Identificou-se que o Brasil possui uma trajetória de iniciativas para expandir e amadurecer suas condições inovativas, no entanto a absorção destas por uma estrutura de subdesenvolvimento mostra-se instigante. Este aspecto contrasta com o discurso de inovação protagonizado pelos países tidos como desenvolvidos, tratado de forma crítica pelo presente artigo. Por fim, argumenta-se que, para que os esforços em inovação transbordem garantindo maiores níveis de desenvolvimento para o Brasil, é necessário que contrariedades e atrasos históricos sejam superados, entendendo que os mesmos obstruem a inovação pretendida.

Palavras-chave: Inovação; Desenvolvimento; Atraso brasileiro.

\begin{abstract}
Innovation has been strategic for stimulating the development process. Aware of this, Brazil has been formulating guidelines to promote its ability to develop technology and innovate, but the results over the years are still modest. This paper aims to allow a logical and discursive discussion on the adequacy of innovation for leveraging the development of underdeveloped economies in the current situation. The study was organized in the form of a theoretical essay, dialoging with the literature that articulates innovation as an element for development, and with data that explore the Brazilian reality. It was identified that Brazil has a trajectory of initiatives to expand and mature its innovative conditions; however, the absorption of these by a structure of underdevelopment is thought-provoking. This aspect is in contrast to the innovation discourse put forth by so-called developed countries, treated critically in this paper. Finally, we argue that for innovation efforts to guarantee higher levels of development for Brazil, it is necessary to overcome historical obstacles and delays, with the understanding that they are barriers to the desired innovation.
\end{abstract}

Keywords: Innovation; Development; Brazilian backwardness.

\section{RESUMEN}

La innovación ha sido estratégica para impulsar el proceso de desarrollo. Consciente de esto, Brasil viene formulando directrices para promover su capacidad para desarrollar tecnología e innovar, pero los resultados a lo largo de los años son todavía modestos. El objetivo de este artículo es permitir una exposición lógica y discursiva acerca de la suficiencia de la innovación como palanca para el desarrollo de las economías subdesarrolladas en la coyuntura actual. El trabajo se organizó en el formato de ensayo teórico, dialogando con la literatura que articula la innovación como elemento para el desarrollo y con datos que exploran la realidad brasileña. Se identificó que Brasil posee una trayectoria de iniciativas para expandir y madurar sus condiciones innovadoras, sin embargo, la absorción de estas iniciativas por una estructura de subdesarrollo se muestra instigadora. Este aspecto contrasta con el discurso de innovación protagonizado por los países considerados como desarrollados, tratado de forma crítica por el presente artículo. Por último, se argumenta que, para que los esfuerzos en innovación conduzcan a mayores niveles de desarrollo es necesario que contrariedades y retrasos históricos sean superados, entendiendo que los mismos obstruyen la innovación deseada.

Palabras clave: Innovación; Desarrollo; Atraso brasileño. 


\section{INTRODUÇÃO}

A demanda por esforços científicos, tecnológicos e de inovação é dominante no contexto atual de mercado globalizado e forte concorrência internacional. A estruturação de condições favoravéis à geração de inovações vem sendo o elemento estratégico de países para o alcance de maiores níveis de competitividade e desenvolvimento, aspecto que coloca à vista a hegemonia dos países desenvolvidos e os desafios a serem superados pelos países subdesenvolvidos, que buscam na geração de inovações a via para o enfrentamento de adversidades econômicas e desafios sociais (Aguirres-Bastos \& Weber, 2018).

Países como China e Coreia do Sul conseguiram nos últimos anos inverter condições de atrasos socioeconômicos em níveis maiores de desenvolvimento apresentando iniciativas que combinam suas estratégias para inovação com a realidade social e econômica do país (Organização das Nações Unidas para a Educação, a Ciência e a Cultura [UNESCO], 2015). Nesse sentido, o papel da inovação no contexto de subdesenvolvimento vem provocar reflexões diante das realidades social e econômica de um cenário global, cujos níveis de desenvolvimento não são homogêneos.

Em sociedades capitalistas industriais, o crescimento das forças de produção veio acompanhado do progresso científico e técnico, associado ao crescente domínio da natureza e da produtividade. As variações no desenvolvimento entre as economias nacionais foram sendo associadas à capacidade de inovação acumulada por cada nação. Com isso, a inovação passa a ser tratada pelos países como elemento-chave para impulsionar o processo de desenvolvimento. A geração, a difusão e o uso da inovação passam a ser interpretados como uma dinâmica complexa, influenciada por fatores, que vão além de atividades de pesquisa e desenvolvimento (P\&D) dentro de grandes corporações privadas (Nelson \& Rosenberg, 1993; Mazzucato, 2014). Para países em condições de subdesenvolvimento, como o Brasil, tem sido considerado determinante garantir condições para que a inovação aconteça (Soares, 2011; Aguirres-Bastos \& Weber, 2018).

Neste sentido, ao longo dos anos, o Brasil vem formulando suas diretrizes de Ciência, Tecnologia e Inovação (CT\&l), passando por diferentes governos e enfoques. A princípio, consciente da necessidade em buscar autonomia tecnológica e maior competitividade, o País acumulou variados planos para orientar os esforços científicos e de tecnologia objetivando o desenvolvimento nacional. Atualmente, considerando as principais tendências mundiais em políticas de CT\&I, o Brasil estabeleceu suas estratégias de médio prazo para a implementação de políticas públicas na área, como constatado no relatório de Estratégia Nacional de Ciência, Tecnologia e Inovação (ENCTI 2016-2022).

Sob esses aspectos, ainda no contexto brasileiro, segundo o ENCTI 2016-2022, o País tem tido avanços, dentre eles: (1) o incremento na qualificação de recursos humanos em diferentes áreas do conhecimento; (2) a ampliação da infraestrutura de pesquisa, buscando a desconcentração e a redução de assimetrias regionais; (3) a criação e 0 aperfeiçoamento dos instrumentos de promoção da pesquisa e da inovação; (4) 0 aumento das publicações científicas por cientistas nacionais; (5) a interiorização de pesquisadores qualificados; e (6) a expansão e a diversificação do financiamento a empresas inovadoras (Ministério da Ciência, Tecnologia, Inovações e Comunicações [MCTIC], 2016b, p. 35). No entanto, o Brasil ainda detém uma posição estagnada em cenário internacional, como lembra Albuquerque (2009) desde 1970.

Portanto, a partir dos esforços realizados de maneira a colocar a inovação como eixo estruturante do seu desenvolvimento nacional e a estagnação brasileira no cenário de inovação ao longo dos anos, emerge o seguinte questionamento, direcionador deste estudo: até que ponto os esforços em inovação realizados pelo Brasil são suficientes, por si só, para inverter sua condição de subdesenvolvimento? Sendo assim, este artigo tem como objetivo promover uma discussão acerca da suficiência da inovação como alavanca para o desenvolvimento no caso brasileiro, argumentando que o País convive com condições sociais e econômicas que obstruem o próprio processo de inovação pretendido. Cabe salientar que metodologicamente 0 artigo configura-se como um ensaio teórico. Como salienta Meneghetti (2011), 0 ensaio tem sido utilizado intencionalmente como via para produzir reflexões sobre acontecimentos relevantes da sua época, tornando-se importante para a formação do conhecimento na atualidade. 0 propósito é tratar o tema de maneira discursiva, não instrumental, optando por não obedecer à divisão e à lógica estabelecida pelas metodologias científicas tradicionais, buscando respostas a partir de afirmações verdadeiras, mas sim instigar provocações, de forma que os leitores tirem livres reflexões e conclusões.

Espera-se, assim, tratar um tema em destaque na conjuntura internacional de maneira crítica, a fim de refletir sobre a demanda atual por inovação, a qual países que convivem com estruturas sociais e econômicas ainda subdesenvolvidas buscam o emparelhamento de seus avanços em CT\&I com os de países desenvolvidos. Acredita-se que tal perspectiva contribui para elucidar a discussão sobre o desempenho estagnado do Brasil ao longo dos anos. Ademais, a reflexão sobre o tema a partir da perspectiva de subdesenvolvimento é um esforço para complementar uma literatura que vai de encontro à ótica, ainda hegemônica, dos países avançados. 
Para alcançar o seu objetivo e as reflexões propostas, o ensaio estrutura-se em cinco seções, sendo a primeira esta introdução. A segunda traz uma síntese teórica de modo a compreender o sentido das nações buscarem por desenvolvimento e o papel da inovação como elemento-chave para que este processo aconteça. Na terceira seção são levantadas as diretrizes brasileiras de CT\&I voltadas para o desenvolvimento nacional nas últimas décadas e, em seguida, a quarta seção visa promover a discussão a respeito da estrutura social e econômica que o País convive, esta que absorve os esforços científicos, tecnológicos e de inovação nacionais, seguindo-se as considerações finais.

\section{A INOVAÇÃO COMO ALAVANCA PARA O DESENVOLVIMENTO DAS NAÇÕES}

Perante a formação de novos processos de produção e expansão das oportunidades de lucro, a formação da riqueza de uma nação fundamentava-se em torno do trabalho produtivo. Para Smith (1996), ao analisar a produção de uma fábrica de alfinetes, as nações enriqueciam via divisão do trabalho, que promovia 0 aprimoramento das forças produtivas que, por conseguinte, contribuíam para a invenção de um grande número de máquinas e incrementos, que resultava no aumento da quantidade do trabalho. Neste sentido, Sunkel e Paz (1976) sintetizam que, diferente de alguns economistas ingleses, que consideravam a riqueza de uma nação como um fundo acumulado, Smith a mediu pelo que pode ser produzido em determinado período de tempo. Nesta concepção, a riqueza das nações estava associada, portanto, à produção, que em conformidade à abundância ou à escassez de bens dispostos, a nação se supriria dos bens e "os confortos de que tem necessidade" (Smith, 1996, p. 59).

Assim como no pensamento smithiano, David Ricardo (1996) defende que a riqueza de uma nação está associada à atividade de produção, com isso, o grau de desenvolvimento de uma economia seria mensurado a partir do produto, entendido como o valor de mercado dos bens produzidos em determinado período de tempo, constituído pela quantidade de trabalho necessária para reproduzi-los. Destaca-se que, de acordo com Ricardo (1996, p. 97), as nações eram detentoras de potencialidades "proporcionadas pela natureza", nas quais sob um sistema comercial "perfeitamente" livre, cada uma dedicaria "naturalmente" seu capital e trabalho às atividades que lhes fossem mais benéficas, ligadas a interesses comuns e de troca. Assim, a busca por uma vantagem individual estaria associada ao "bem universal do conjunto dos países". Para Ricardo (1996, p. 97), "este é o princípio que determina que o vinho seja produzido na França e em Portugal, que o trigo seja cultivado na América e na Polônia, e que as ferramentas e outros bens sejam manufaturados na Inglaterra".

As teorias econômicas foram se debruçando na identificação das variáveis que tivessem efeito sobre o alcance de maiores níveis de desenvolvimento econômico. Modelos que explicavam o desempenho de uma economia a partir da atividade produtiva foram sendo repensados. Ao longo do tempo, percebeu-se que a maior parte da variação na produção não se explicava permanentemente pelas variáveis capital e trabalho, senão pelo que se denominou de "mudança técnica". Os economistas foram tornando-se mais conscientes do papel decisivo da tecnologia, incluindo-a como um elemento importante nos modelos que buscavam compreender a economia (Mazzucato, 2014).

Sob o panorama de ascensão do sistema de "maquinofatura", Rosenberg (2006) recorre à Marx como estudioso da tecnologia para recuperar a atenção dada à importância das mudanças tecnológicas no modo de produção capitalista. Para Marx, as relações capitalistas emergiram quando o crescimento das oportunidades de lucro levou a uma expansão do tamanho das unidades produtivas para além do tamanho característico da oficina de artesanato medieval. $O$ aumento da produtividade acompanha, assim, a história de formação e desenvolvimento do modo de produção capitalista, em que a tecnologia seria aquilo que medeia a relação entre o homem e o mundo exterior material, constituindo um assunto de interesse não apenas para os tecnológos, mas também para os estudiosos da sociedade (Rosenberg, 2006). Segundo Marx (2013), a introdução de máquinas cada vez mais aperfeiçoadas no processo de trabalho foi responsável pelo desenvolvimento da produtividade e, consequentemente, trouxe implicações econômicas e sociais. Esta perspectiva rompe com a visão de encarar o papel da manufatura estritamente em panorama produtivo, sob um "fetichismo da manufatura", para, então, considerar o modo de produção capitalista como algo a ser pensado e aceito como um fenômeno social, que passa por uma "revolução ininterrupta dos meios de produção", que promove transbordamentos econômicos e sociais (Marx, 2013, p. 68).

Para que o capitalismo tenha sua máquina funcionando, segundo Schumpeter (1962), seria fundamental que 0 processo produtivo, em sentido amplo, introduzisse o que se chamou de "novas combinações", introduzindo, assim, inovações. Considera-se como combinações uma empresa como tal, bem como as condições produtivas de todo um sistema econômico. Sob este panorama, a promoção de inovações ganha protagonismo na compreensão do desenvolvimento de empresas e nações. 
Capitalism, then, is by nature a form or method of economic change and not only never is but never can be stationary (...). the fundamental impulse that sets and keeps the capitalist engine in motion comes from the new consumers' goods, the new methods of production or transportation, the new markets, the new forms of industrial organization that capitalism enterprise creates (Schumpeter, 1962, pp. 82-83).

Ademais, tem-se que o pensamento schumpeteriano avança na compreensão do desenvolvimento de economias nacionais para além da fronteira economicista, que considera elementos estritamente quantitativos que se relacionam sob um ambiente de perfeito equilíbrio. Com isso, os fatores que levariam ao alcance de maiores patamares de desenvolvimento não seriam explicados apenas por circunstâncias econômicas prévias que se mantêm constantes, que segundo Schumpeter, jamais são atingidas, senão por transformações econômicas espontâneas e descontínuas (Schumpeter, 1961, 1962).

Neste sentido, tem-se, a partir da inserção de inovações, o processo de "destruição criativa", isto é, a substituição de antigos produtos e hábitos de consumo por novos. Nesta visão, o mercado é caracterizado por grande concorrência, cujas empresas encontram-se em condições distintas de competição e estão sujeitas a uma espécie de seleção natural e, portanto, devem se adaptar ao ambiente a fim de sobreviverem. Desse modo, o fundamental do processo de desenvolvimento de uma nação seria o papel desempenhado pela inovação, que leva a mudanças qualitativas na organização do sistema econômico (Schumpeter, 1962; Pivoto et al., 2016).

Freeman (1988) considera a visão schumpeteriana uma tentativa fundamental de constituir uma teoria alternativa para explicar o desenvolvimento de certas economias. No entanto, considera que esta tentativa não foi de total suficiência. Neste sentido, segundo Freeman (1988), Schumpeter deu pequena atenção aos países considerados subdesenvolvidos, suas análises não se estenderam à compreensão da competição tecnológica no contexto de difusão internacional da tecnologia, além de pouco tratar sobre políticas governamentais para a indústria, ciência e tecnologia. 0 posicionamento de Freeman e outros economistas conhecidos como neoschumpeterianos se dá mediante a necessidade de desenvolver, a partir das ideias schumpeterianas, outros desdobramentos.

A corrente neoshumpeteriana contribuiu para os alicerces da chamada teoria evolucionista da inovação e colocou o processo inovativo dentro de uma perspectiva dinâmica e de significativa complexidade institucional. Richard R. Nelson e Sidney Winter, no ensaio In search of useful theory of innovation (1977), dão indícios da importância da difusão da inovação como elemento de competividade, uma vez que as empresas encontram-se em ambiente de seleção e de concorrência dinâmica, em que uma inovação considerada bem-sucedida leva a oportunidades lucrativas, dessa maneira, as empresas crescem e "cortam" do mercado as não inovadoras, forçando-as a inovar.

Ainda sob abordagem neoschumpetriana, o conceito de inovação é ainda expandido e, com estudiosos como Freeman (1989), Lundvall (1992) e Nelson (1993), a concepção de inovação passa a ser tratada como uma dinâmica sistêmica, emergindo assim o marco teórico de Sistema Nacional de Inovação (SNI), em que diferentes atores, de naturezas variadas, se interagem para a produção, a difusão e o uso de novos conhecimentos economicamente úteis, bem como para o desenvolvimento, a importação, a modificação e a difusão de novas tecnologias. A geração, a difusão e 0 uso da inovação passam a ser interpretados por diferentes fatores, que vão além de atividades de P\&D dentro de grandes corporações privadas (Freeman, 1988; Lundvall, 1992; Mazzucato, 2014).

Segundo Nelson e Rosenberg (1993), o interesse nesta concepção dinâmica da inovação tornou-se maior diante a crença que as variações no desempenho das economias nacionais eram explicadas pelas características distintivas entre as capacidades de inovação dos países. Os autores evidenciavam que este interesse se confirmava em uma conjuntura global em que países industrialmente avançados se preocupavam com a desaceleração de suas economias, que vinha acontecendo desde o início dos anos de 1970, enquanto outros apresentavam competitividade ascendente em campos produtivos que costumavam a pertencer estritamente à Europa e aos Estados Unidos. Neste contexto, existia 0 que foi denominado por Nelson e Rosenberg (1993) de "tecnonacionalismo", em que as políticas para o fomento de tecnologia eram apontadas como meio para tornar as indústrias mais competitivas, entendendo que isso seria resultado das capacidades inovativas acumuladas pelo próprio país.

Porter (1990), ao tratar a vantagem competitiva das nações, afirma que a prosperidade de uma região é conquistada e não herdada. Neste sentido, Porter (1990) parte que as nações encontram-se em um cenário de competitividade global muito acirrado, que tende a ficar cada vez mais competitivo, impulsionado pela capacidade das indústrias realizarem inovações e melhorias. Sob esta concepção de competição, entende-se que o papel dos países na assimilação de conhecimentos economicamente úteis para a geração e absorção de inovação tornou-se mais central. Além de que as diferenças em valores nacionais, cultura, estruturas econômicas, instituições e aspectos históricos contribuem para a capacidade de um país promover inovações em sua estrutura produtiva. 
There are striking differences in the patterns of competitiveness in every country; no nation can or will be competitive in every or even most industries. Ultimately, nations succeed in particular industries because their home environment is the most forward-looking, dynamic, and challenging (Porter, 1990, p. 73).

A dinâmica concorrencial que escora 0 desenvolvimento das economias do mundo teria transbordado no processo de abertura econômica pós Segunda Guerra Mundial (Porter, 1990; Bresser-Pereira, 2008). Segundo Kaldor (1957, p. 3), no pós-guerra os países teriam adquirido uma "consciência-desenvolvimento". A então consolidação do sistema-mundo capitalista (Gaspar, 2015) deixava claro que os países pertenciam a níveis de desenvolvimento heterogêneos (Gala, 2017). Havia os países de "centro" e "periferia", destacados sob uma "divisão internacional do trabalho" disseminada como ordem comercial mundial. A ideia de que os países subdesenvolvidos eram os especialistas em fornecer matéria-prima para os países avançados industrialmente era uma premissa que prejudicava 0 desenvolvimento econômico. Tinha-se que este aspecto interferia na manifestação das capacidades para gerar crescimento e desenvolvimento por alguns países (Prebisch, 1949; Furtado, 1978; Gala, 2017). Lundvall (1988) ainda salientou que, mesmo diante da abertura do mercado internacional para o capital, comércio e produção, as particularidades de cada país com seus padrões de especialização, condições institucionais e preceitos culturais não foram necessariamente eliminadas.

Este cenário capitalista globalizado incentiva movimentação tecnológica, estimulando o surgimento de novos paradigmas que permitem novas oportunidades tecnológicas. Em um novo paradigma tecnoeconômico, alguns países têm a oportunidade de tomarem a liderança do desenvolvimento (forging ahead), enquanto outros podem buscar 0 emparelhamento (catching up) com países mais desenvolvidos ou também podem não se engajar na nova dinâmica, ficando para trás (falling behind) (Albuquerque, 2009; Arend \& Fonseca, 2012). Por outro lado, Albuquerque (2009) ressalta que a movimentação da fronteira tecnológica internacional aumenta a lacuna tecnológica entre as nações. Sob ambiente de competição os países mais ricos buscam preservar suas vantagens competitivas em mercados de seus interesses (Gala, 2017). Neste sentido, ao considerar uma perspectiva histórica, Chang (2004) defende que os países mais avançados buscam "chutar a escada" pela qual usaram para chegar ao desenvolvimento, de modo a impedir que os países subdesenvolvidos adotem as políticas e as instituições que usaram.

Diante do objetivo político de perseguir o desenvolvimento, volta-se a atenção à capacidade das nações, que por meio do seu Estado irá formular uma estratégia nacional de desenvolvimento para competir internacionalmente (Bresser-Pereira, 2008). Nas últimas décadas, as políticas para influenciar as atividades de geração de conhecimento, desenvolvimento tecnológico e difusão de inovações emergiram como um novo campo de política econômica, com 0 objetivo de impulsionar o desenvolvimento (Fagerberg, 2017). Schot e Steinmueller (2018) afirmam que as diretrizes voltadas para a formulação e implementação de políticas para a geração e absorção de inovação estiveram moldadas em três principais enquadramentos associados à conjuntura global, que correspondem (1) à institucionalização do apoio do governo à ciência e à pesquisa no pós-guerra; (2) ao processo de globalização da década de 1980, cuja ênfase é dada aos sistemas nacionais de inovação e à comercialização do conhecimento; e (3) aos desafios sociais e ambientais contemporâneos, imputando nas ações planejadas o desígnio de concretizar um desenvolvimento sustentável, isto é, que concilie aspectos econômicos, sociais e ambientais.

Ainda neste sentido, vem emergindo a perspectiva da inovação como promotora de desenvolvimento inclusivo, o qual atende objetivos de crescimento econômico e avanço em questões sociais paralelamente. A chamada "inovação inclusiva" emerge como alternativa ao pensamento dominante, concentrado no desenvolvimento econômico. Nesta perspectiva, ainda emergente, novos bens e serviços são desenvolvidos para e/ou por aqueles que foram excluídos do mainstream do desenvolvimento - aqueles que vivem com as rendas mais baixas (Aguirres-Bastos \& Weber, 2018; Heeks, Foster \& Nugroho, 2014; Heeks, Amalia, Kintu \& Shah, 2013).

\section{AS DIRETRIZES BRASILEIRAS PARA INTERAÇÃO ENTRE CIÊNCIA, TECNOLOGIA E INOVAÇÃO E 0 DESENVOLVIMENTO NACIONAL NOS ÚLTIMOS 40 ANOS}

As ações de planejamento realizadas pelo Estado brasileiro de modo a perseguir maiores níveis de desenvolvimento, por meio de esforços inovativos, são materializadas, como ponto de partida, pela elaboração do Plano Básico de Desenvolvimento Científico e Tecnológico (PBDCT) para os anos de 1973 e 1974, aprovado pela Presidência da República por meio do decreto 72.527, de 25 de julho de 1973, cujo sentido, nas próprias palavras do Ministro do Planejamento e Coordenação, João Paulo dos Reis Velloso, em pronunciamento ao presidente General Emílio Médici, era "colocar ciência e tecnologia modernas a serviço da sociedade brasileira, nos seus objetivos de desenvolvimento e de grandeza" (Cavalcante, 2009; Brasil, 1973, p. 5). 
De acordo com Velloso, o I PBDCT era a definição de uma política de ciência e tecnologia que objetivava acompanhar o progresso científico mundial e obter uma tecnologia mais atualizada. Esperava-se que o plano então desenvolvido fosse uma ação que conduzisse à ideia de modernização, traçando os rumos para uma economia mais competitiva. Para isso, a política científica e tecnológica brasileira seria executada nas áreas de: I) desenvolvimento de novas tecnologias (energia nuclear, pesquisa espacial, oceanografia) e novas indústrias tecnológicas (eletrônica, química e aeronáutica); II) fortalecimento da capacidade de absorção e criação de tecnologia pelas empresas nacionais (públicas e privadas); III) consolidação da infraestrutura de pesquisa científica e tecnológica, principalmente na área governamental (no âmbito federal destacava-se o Instituto Nacional de Tecnologia, o Instituto Nacional de Propriedade Industrial, 0 Instituto Nacional de Pesos e Medidas, a Empresa Brasileira de Pesquisa Agropecuária, a Diretoria de Pesquisa e Ensino Técnico do Exército, o Instituto de Pesquisas da Marinha, Centro Técnico Aeroespacial, Institutos ligados ao Conselho Nacional de Desenvolvimento Científico e Tecnológico (CNPq), os Centros de Pós-Graduação do Ministério da Educação e a Fundação Oswaldo Cruz; IV); consolidação do sistema de apoio ao desenvolvimento científico e tecnológico; e V) integração Indústria-Pesquisa-Universidade (Brasil, 1973, pp. 7-11).

Mesmo que objetivos econômicos fossem identificados por traz da ideia de uma indústria mais moderna e uma economia mais consolidada, o progresso científico e tecnológico no referido momento foi colocado como importante elemento para a organização do processo de intensa urbanização da época, para a superação da agricultura tradicional, para a integração das regiões nacionais e para a atuação social nas áreas de educação, saúde, saneamento e distribuição de renda (Brasil, 1973).

No governo do general Ernesto Geisel, foi aprovado em 31 de março de 1976, pelo decreto 77.355, o II PBDCT, cujo enfoque era a aplicação de recursos às atividades de ciência e tecnologia do país até 1979, contanto com um orçamento trienal (revisto anualmente). As diretrizes estabelecidas complementavam o segundo Plano de Desenvolvimento do País (II PND) e tinham como frentes principais a criação de instrumentos que possibilitassem as empresas nacionais competirem com as empresas estrangeiras. Para isso, tinha-se como objetivo a criação da empresa Investimentos Brasileiro S.A. (IBRASA), Mecânica Brasileira S.A. (EMBRAMEC) e Financiamentos e Participações S.A. (FIBASE), o Programa Nacional de Treinamento de Executivos (PNTE), o Centro Brasileiro de Assistência Gerencial à Pequena e Média Empresa (Sistema CEBRAE) e a expansão de atuação da Financiadora de Estudos e Projetos (Finep) (Brasil, 1976).

Além de diretrizes básicas de estratégia econômica, o II PBDCT afirmava considerar importante: I) definir o perfil econômico desejado no Brasil sob uma política de substituição de importações; II) ter uma estratégia agropecuária de maior contribuição para o Produto Interno Bruto (PIB), além de outras ações associadas ao perfil da produção agrícola e a qualidade da vida no campo; III) formular uma política de energia para aumentar o preço do petróleo e diminuir a dependência nacional de fontes energéticas externas; IV) avançar no desenvolvimento de novas tecnologias e da qualidade tecnológica das empresas nacionais; entre outros programas setoriais (Brasil, 1976, pp. 9-19).

Já com a finalidade de orientar as ações executadas pelo País entre 1980 e 1985, foi elaborado o III PBDCT. 0 plano surge por meio de um documento formulado pelo CNPq e complementado pelo Conselho Científico e Tecnológico (CCT), dando um caráter participativo e reflexivo às diretrizes estabelecidas. A política de ciência e tecnologia para 0 período tinha como objetivo a "busca da melhoria das condições de vida da população com o foco em conseguir maior capacitação científica (ampliação do quadro de pesquisadores, expansão da pós-graduação, política nacional de educação e formação de recursos humanos) e maior autonomia tecnológica (geração interna de tecnologia)" (Brasil, 1980, p. 13).

Em relação à organização do Estado brasileiro, em 15 de março de 1985, pelo decreto 91.146, foi criado o Ministério da Ciência e Tecnologia (MCT), que pela Lei 7.739 de 16 de março de 1989 teve suas atribuições fundidas ao Ministério do Desenvolvimento Industrial, Ciência e Tecnologia, durante o governo de José Sarney que, posteriormente, foram confiadas à Secretaria Especial de Ciência e Tecnologia, criada em 21 de março de 1989 pela Lei 7.740 (MCTIC, n.d). De acordo com Manini (2015), o MCT voltou a existir ainda em 1989, porém, um ano depois, no governo Collor, foi novamente extinto, devido a uma política de corte de gastos governamentais, ressurgindo apenas em 1992 no governo Itamar Franco, por meio de uma medida provisória. Em agosto de 2011, o MCT passa a ser nomeado Ministério da Ciência, Tecnologia e Inovação (MCTI), que em maio de 2016 foi transformado em Ministério da Ciência, Tecnologia, Inovações e Comunicações (MCTIC), com a extinção do Ministério das Comunicações em setembro de 2016.

Já nos 2000, foi criado o documento de "Diretrizes de Política Industrial, Tecnológica e de Comércio Exterior" com o objetivo de aumentar o desempenho econômico e tecnológico nacional, explicitando o propósito do País em conquistar maior competividade no cenário internacional. Logo, esforços relacionados ao aumento da eficiência da estrutura produtiva, melhoria da capacidade de inovação das empresas brasileiras e expansão das exportações eram apontados. Este aspecto ratifica o que Cavalcante (2009) traz em seu estudo ao colocar que as políticas voltadas para 
as áreas de CT\&I têm sido apresentadas como componente fundamental das políticas industriais e de comércio exterior. Cabe ressaltar que a política aqui exposta também era considerada parte das ações governamentais apresentadas no documento de Orientação Estratégica de Governo e também era integrada com as medidas previstas em Plano Plurianual (PPA) (Ministério da Indústria, Comércio Exterior e Serviços [MDIC], 2003).

As orientações acima vão ao encontro de cinco frentes principais: I) inovação e desenvolvimento tecnológico (estruturar um Sistema Nacional de Inovação que permita a articulação de agentes voltados ao processo de inovação do setor produtivo); II) inserção externa (expansão das exportações e ampliação da base exportadora - incorporação de novos produtos, empresas e negócios); III) modernização industrial (financiamento para aumento de capacidade das indústrias nacionais, modernização de equipamentos, programas de modernização de gestão, melhoria de design, apoio ao registro de patentes e de extensão tecnológica); IV) capacidade e escala produtiva (apoio de políticas públicas); e V) opções estratégicas (fomento de esforços em áreas intensivas em conhecimento, como semicondutores, software, fármacos e medicamentos e bens de capital) (MDIC, 2003).

Posteriormente, o Plano de Ação em Ciência, Tecnologia e Inovação 2007-2010 (PACTI) é elaborado para incentivar a interação entre os atores do sistema de inovação brasileiro, sendo apresentadas como prioridades: I) expansão e consolidação do sistema nacional de CT\&l; II) promoção da inovação tecnológica nas empresas; III) pesquisa, desenvolvimento e inovação em áreas estratégicas; e IV) ciência, tecnologia e inovação para o desenvolvimento social.

Ainda de acordo com o documento, a ênfase na ampliação e na otimização dos recursos investidos em CT\&l, a maior consciência do setor empresarial sobre a importância da inovação e do investimento privado em P\&D e a articulação de entidades do Estado para o aumento da capilaridade das ações na área são alguns dos avanços conquistados. Ademais, o PACTI parte de um plano de transversalidade com outras políticas de Estado, a exemplificar os planos de desenvolvimento da educação, saúde e agropecuária (MCT, 2010).

Anos seguintes é elaborado o Plano Brasil Maior 2011-2014, a fim de buscar maiores índices de competitividade da indústria nacional, estabelecendo, portanto, diretrizes para a elaboração de programas e projetos em parceria com a iniciativa privada. A interação entre diferentes agentes era pressuposto importante do plano, que propunha "mobilizar as forças produtivas para inovar, competir e crescer" e "aproveitar as competências presentes nas empresas, na academia e na sociedade, a fim de construir um país mais próspero e inclusivo" (MDIC, 2011, p. 8). Isto corrobora com estudos realizados que compreendem que a implementação de políticas para a inovação não vem se restringindo mais às esferas governamentais e acadêmicas (Cavalcante, 2009; Turchi \& Arcuri, 2017).

Em relação ao fortalecimento dessa articulação, a partir de 2012 o governo federal passou a lançar a Estratégia Nacional de Ciência, Tecnologia e Inovação (ENCTI 2012-2015). O documento em sua primeira edição ressalta a importância do fomento à CT\&l e, por isso, orienta ações científicas, tecnológicas e inovativas para o desenvolvimento do País em médio prazo (MCTI, 2012). Como forma de dar continuidade e reformular estas iniciativas, foi elaborada a ENCTI 2016-2019, com enfoque em direcionar de forma estratégica a execução de políticas públicas (MCTIC, 2016a). Sob o governo pós-impeachment, o MCTIC revisou e "atualizou" a estratégia nacional para o período 2016-2022, entendendo a necessidade de o País alcançar um novo patamar de desenvolvimento por meio da construção de uma sociedade do conhecimento (MCTIC, 2016b). Atualmente, o documento desdobra a estratégia nacional em frentes de atuação consideradas estratégicas, afirmando realizar um balanço envolvendo representantes do governo, sociedade civil e setor produtivo para avaliar sua implementação ao final do período de vigência (2022).

Entre os desafios a serem superados pelas diretrizes nacionais atuais, destacam-se: (1) posicionar o Brasil entre os países com maior desenvolvimento em CT\&I; (2) aprimorar as condições institucionais para elevar a produtividade a partir da inovação; (3) reduzir assimetrias regionais na produção e no acesso à CT\&l; (4) desenvolver soluções inovadoras para a inclusão produtiva e social e (5) fortalecer as bases para a promoção do desenvolvimento sustentável (MCTIC, 2016b).

\section{A SUFICIÊNCIA DOS ESFORÇOS EM INOVAÇÃO PARA MUDAR A CONDIÇÃO DE ATRASO BRASILEIRA}

Kuznets (1985) salientava que, ao longo dos séculos, o ritmo pelo qual o progresso e o desenvolvimento aconteceram foi distinto entre as regiões do mundo. E ainda que o desenvolvimento científico, tecnológico e de inovação, trazido aqui como elemento importante, seja necessário, não é condição suficiente. A ideia de Kuznets promove uma reflexão ao trazer que, para estimular seu próprio desenvolvimento, os países devem considerar a necessidade de realizar adaptações institucionais e ideológicas ao seu próprio contexto.

Este aspecto imputa uma discussão importante ao considerar o que Chang (2004) apontou: os países desenvolvidos e as políticas internacionais exercem significativas pressões sob os países subdesenvolvidos, estes que 
passam a conviver com a demanda em adotar as "boas práticas" desse grupo de referência. Consciente da necessidade de fomentar a inovação, o Brasil demonstra perseguir o emparelhamento do País com nações mais avançadas e salienta que "aproximar as iniciativas nacionais de CT\&I daquelas identificadas como tendências mundiais é um passo importante para o avanço tecnológico, econômico e social do País" (MCTIC, 2016b, p. 59).

Chang (2004) ainda toma um posicionamento crítico ao entender que a implementação de políticas industrial, comercial e tecnológica (ICT) não garante que os países alcancem o desenvolvimento almejado. Ainda segundo o autor, a capacidade de se chegar ao objetivo de desenvolvimento seria pela maneira como essas políticas são constituídas e a capacidade que o Estado possui em implementá-las. Nesse contexto, Furtado (2009) já salientava sobre a necessidade de considerar a realidade nacional à finalidade de perseguir o desenvolvimento.

Nas últimas décadas, a China constituiu um projeto de desenvolvimento que dá protagonismo ao progresso científico e tecnológico, com políticas de desenvolvimento que orientam o país para a inovação. A estratégia chinesa, principalmente a partir dos anos 2000 , teve como objetivo ter o mercado interno como referência para desenvolver novos rumos tecnológicos voltados às características específicas da economia e da sociedade chinesa (Cassiolato, 2013). Por meio do estudo comparativo entre a agenda de inovação chinesa e brasileira e suas múltiplas lições, pode-se apontar que a inovação é encarada como uma estratégia de desenvolvimento, no entanto não tem fim em si mesma, ou seja, os esforços de inovação prosperam quando absorvidos por uma estrutura sólida em competitividade, junto com outros aspectos a destacar, como a continuidade de planejamento e a capacidade em formular políticas efetivas. A China possui um Plano de Médio e Longo prazo para o desenvolvimento da Ciência e Tecnologia (2006-2020) e, segundo Pacheco (2011), o país encara a inovação e o desenvolvimento tecnológico como elementos de uma estratégia nacional econômica e não como parte agregada de uma agenda de ciência e tecnologia.

A Coreia do Sul, diferente de adotar práticas dos países centrais, tentou mudar o paradigma vigente, ao concentrar esforços no segmento da economia criativa e tecnologias verdes, sustentáveis, criando tecnologias próprias (Jones \& Yoo, 2011). O país apresentou importantes resultados em relações a outros países, como Alemanha, Estados Unidos e a própria China, por exemplo, em dispêndios nacionais em P\&D em relação ao PIB. Ainda em comparação internacional, a Coreia do Sul vem apresentando comportamentos semelhantes a países como Japão e Estados Unidos em relação ao financiamento de P\&D por parte do governo, empresas privadas e outras entidades em geral e em movimento ascendente em seus resultados de pedidos e concessões de patentes (MCTIC, 2017).

De forma a materializar seus esforços científicos e tecnológicos, o Brasil vem apresentando crescimento contínuo em alguns dos seus indicadores de CT\&I, a destacar o número de pesquisadores e pessoal de apoio envolvidos em P\&D, concluintes de cursos de graduação e pós-graduação, produção científica (produção de artigos e citações brasileiras) e pedidos de patentes de invenção ao Escritório Americano de Marcas e Patentes (USPTO). Porém, os demais indicadores, em sua maioria, apresentam visível queda, principalmente a partir de 2013 (Brasil, 2017).

No cenário internacional, por meio do Global Innovation Index, sob a escala de 0 a 100, em 2017, Suíça $(67,69)$, Suécia $(63,82)$, Países Baixos $(63,36)$, Estados Unidos $(61,40)$, Reino Unido $(60,89)$, Dinamarca $(58,70)$, Singapura $(58,69)$, Finlândia $(58,49)$, Alemanha $(58,39)$ e Irlanda $(58,13)$ tiveram os melhores desempenhos no campo da inovação. China e Coreia do Sul, casos destacados acima, alcançaram a $22^{\mathrm{a}}$ e $11^{\mathrm{a}}$ posições, respectivamente, enquanto 0 Brasil veio alcançando nos últimos anos as posições $66^{\circ}(2019), 64^{\circ}$ (2018), 69 $(2017), 69^{\circ}$ (2016), $70^{\circ}(2015), 61^{\circ}(2014)$ e $64^{\circ}$ (2013).

O relatório da Unesco publicado em 2015, que perpassa pelo desempenho e pela orientação de CT\&l em diferentes países, proporciona uma visão geral das dificuldades enfrentadas pelo Brasil, assim como a contramão que se segue em relação a outros países, destacando para a presente discussão a maneira de governança das instituições brasileiras, principalmente públicas, que ainda seguem regras rígidas que dificultam sua administração e os resultados modestos que sugerem que o Brasil ainda não conseguiu aproveitar a inovação para impulsionar seu desenvolvimento.

É notável que o desempenho global de inovação mostra os melhores índices a países que também apresentam estruturas socioeconômicas, já de conhecimento, maduras. Curiosamente, o próprio índice de inovação global referido anteriormente considera para a mensuração do desempenho dos 127 países analisados, entre múltiplos fatores, aspectos como ambiente político, qualidade regulatória, educação (não apenas ensino superior), inclusão digital, infraestrutura de informação, desempenho ambiental, escala do mercado interno, difusão de bens e serviços criativos, entre outros. 0 que se quer deixar como reflexão é o que bem afirma Albuquerque (2009, p. 72):

Superar a tecnologia subdesenvolvida é um fator-chave, mas não é suficiente. Subdesenvolvimento não é uma mera consequência da falta de instituições, por isso sua superação não é apenas uma questão de "construção de instituições". O processo de desenvolvimento não é apenas quantitativo 
(mais recursos, mais instituições, etc.). Há passos qualitativos decisivos que parecem ser precondição para todo o processo de desenvolvimento.

O autor ainda propõe que uma estratégia de desenvolvimento na qual o país deve realizar a combinação entre a construção de uma base técnico-científica para alimentar o processo de desenvolvimento; a superação de obstáculos, como a concentração de renda e a ausência da formação de capacitações educacionais, técnicas e científicas; e, por fim, garantir um ambiente de inclusão social, de diversidade e pluralidade (Albuquerque, 2009).

Quando tais ideias são encaixadas no contexto brasileiro, não é o objetivo não reconhecer os avanços e os esforços realizados pelo Brasil. Porém, sabe-se que determinados países apresentam limitações que impõem dificuldades aos seus esforços para inovação (Aguirre-Bastos \& Weber, 2018). Neste sentido, salienta-se que as iniciativas e políticas nacionais de CT\&I convivem com uma estrutura social e econômica retardatária e contrariedades a serem superadas.

Segundo a Síntese de indicadores sociais em 2017, é possível identificar alguns comportamentos que contradizem o alcance de uma estratégia efetiva de inovação que leve ao desenvolvimento. A população brasileira convive com uma taxa de desocupação em forte crescimento, como constatado em 2015 e 2016, configurando um movimento de saída de trabalhadores da situação de ocupação para desocupação junto à descontinuidade do crescimento dos empregos com vínculo formal, que vinha acontecendo desde 2012. A participação dos trabalhadores com 16 anos ou mais de idade se dá de maneira desigual entre as regiões brasileiras e há visíveis diferenças destes resultados entre pretos, pardos e brancos, evidenciando maior vulnerabilidade entre pretos e pardos.

A maior informalidade do mercado de trabalho das Unidades Federativas das Regiões Norte e Nordeste se traduz em elevado contingente de trabalhadores sem acesso aos mecanismos de proteção social que estão relacionados à formalização, deixando-os, portanto, mais vulneráveis a situações adversas como, por exemplo, a doenças e à desocupação. Da mesma forma, inibe o acesso dos mesmos a direitos básicos como a remuneração pelo salário mínimo, além de dificultar 0 acesso à aposentadoria (Instituto Brasileiro de Geografia e Estatística [IBGE], 2017, p. 34).

Ao se ter conhecimento dos planos formulados pelo Brasil buscando a modernização de sua economia, como visto na terceira seção, é observada tamanha contrariedade da estrutura brasileira ao identificar que 1,8 milhão de crianças entre 5 e 17 anos compõem uma realidade de trabalho infantil (IBGE, 2016). Tão contraditório quanto se ter conhecimento que, segundo Siqueira (2010), o trabalho escravo ainda faz parte da realidade brasileira no século XXI, isto é, pessoas estão subjugadas a trabalho forçado ou obrigatório e/ou trabalho realizado em condições degradantes.

Ainda nessa linha, para reflexão, a informalidade é uma característica presente historicamente no contexto brasileiro e considerada um elemento relevante da desigualdade nacional, entendendo ser responsável pela propagação das desigualdades entre as regiões do território nacional e em grupos populacionais específicos. 0 país ainda apresenta condições desiguais de padrão de vida e distribuição de renda, onde há acesso desigual a recursos econômicos, em particular, considerando o rendimento domiciliar per capita (RDPC). Em 2016, entre as pessoas com os 10\% menores rendimentos, pretos ou pardos eram 78,5\%, contra 20,8\% de brancos (IBGE, 2017). Os dados socioeconômicos brasileiros ainda mostram significativa parcela de pessoas sem acesso à educação, à proteção social, à moradia adequada, aos serviços de saneamento básico e à comunicação (internet), sendo $64,9 \%$ da população brasileira, em 2016, apresentando algum tipo dessas restrições (IBGE, 2017).

Por meio do estudo realizado pela Organisation for Economic Co-operation and Development (OECD), Education at a Glance 2017, percebem-se contradições no campo educacional brasileiro ao mostrar a baixa participação de crianças na educação básica em relação aos países que compõem a organização e, inclusive, outros países da América Latina. Os gastos totais em educação se equiparam a outros países do mundo, no entanto não refletem o dispêndio de recursos por alunos, que é considerado muito abaixo. Mais de $50 \%$ das pessoas entre 25 a 64 anos no Brasil não atingiram 0 ensino médio, mais que o dobro da OECD (OEDC, 2017).

A população ainda tem dificuldades em acesso a cuidados básicos. Segundo a OCDE (2015), é colocado à disposição da população um sistema brasileiro de saúde pública subfinanciado, que deixa visível a necessidade de maior eficiência de recursos e qualidade de seus serviços, além de um sistema tributário que não desempenha o papel de redistribuição de renda. Ademais, Filgueiras (2009) salienta que o cenário político brasileiro tem sido caracterizado por instabilidade política e recorrentes casos de corrupção, que carece não apenas de mudanças na máquina pública, mas também o reforço da cultura política democrática da população. 
Como lembra Furtado (2009), quando se manusea o fenômeno do subdesenvolvimento, lida-se por si só com um desequilíbrio de diferentes fatores, inferindo que suas estruturas compõem um sistema híbrido. Ao estar diante de um discurso global que coloca todos no patamar da necessidade por inovar, em países como o Brasil, iniciativas científicas, tecnológicas e de inovação devem transbordar para superar obstáculos, bem como os avanços tecnológicos não devem estar dissociados dos esforços, também necessários, de desenvolver frentes básicas que terão a capacidade de absorver as políticas de CT\&l. Furtado (2009) lembra que o desenvolvimento de uma economia subdesenvolvida implica em modificações estruturais. A definição de uma política de inovação considerada eficaz ocorre diante da necessidade de se moldar à complexidade que constituem a realidade (Aguirre-Bastos \& Weber, 2018).

\section{CONSIDERAÇÕES FINAIS}

Sob um panorama dinâmico e competitivo, os países, que partem de capacidades inovativas distintas, buscam formular suas estratégias de desenvolvimento para competirem internacionalmente e/ou terem a oportunidade de tomarem a liderança do desenvolvimento. Diante da demanda em adotar boas práticas advindas da realidade de países avançados, refletir acerca da aborção dos esforços para inovação em uma estrutura subdesenvolvida mostrou-se instigante. Ademais, a expectativa em inverter a condição de atraso é aguçada quando certos países subdesenvolvidos vêm conquistando, por esforços científicos, tecnológicos e de inovação, maiores índices de competitividade e, assim, a inovação se torna atraente em ser o "trampolim" para outras nações retardatárias.

O Brasil mostrou estar engajado nesta dinâmica e vem realizando esforços para a integração entre inovação e desenvolvimento nacional. Políticas e planos foram formulados ao longo de diferentes governos e enfoques. Considerando a constituição de tais esforços, chama-se a atenção à importância dada ao emparelhamento do País com aqueles países já desenvolvidos, bem como ao período temporal de curto prazo das políticas formuladas e os rompimentos já apresentados na organização do Estado brasileiro ao longo da história para a execução das diretrizes de CT\&l. Este contexto pode contribuir para a percepção de intensidade de esforços em inovação, porém reflete uma posição estagnada no que tange a seus resultados ao longo dos anos.

O ensaio passa a argumentar que o processo de inovação por si só não é suficiente, sendo necessário constituir uma estrutura capaz de absorver as estratégias formuladas. Até que ponto os esforços, e inclusive os avanços, em CT\&I realizados pelo Brasil resultarão na melhoria da condição nacional de desenvolvimento, sendo que sua estrutura, em termos básicos, não superou muito dos seus atrasos?

Resultados sobre a realidade da população brasileira evidenciam variados obstáculos aos esforços de inovação realizados. Mesmo aproveitando oportunidades geradas por novas fronteiras tecnológicas, a população ainda tem dificuldades em acesso a cuidados básicos, a demanda por um estrutura produtiva mais sofisticada convive com alarmantes realidades de trabalho infantil e trabalho escravo. A geração de novos conhecimentos e saltos tecnológicos pelo País convive com contradições em seu sistema educacional, baixa participação de crianças na educação básica e alta taxa de pessoas sem completar o ensino médio.

Ainda neste sentido, a busca por maiores patamares de desenvolvimento relaciona-se com altas taxas de desocupação e informalidade, além da necessidade de maior eficiência de recursos e qualidade de serviços básicos e cenário político instável. Deste modo, superar questões estruturais ainda relacionadas à desigualdade de renda, desigualdade das condições de vida e distribuição de recursos, diminuição da disparidade entre grupos sociais pelo tipo de raça ou sexo, a continuidade e maior consistência das políticas formuladas, a atenção não apenas em resultados quantitativos, mas também qualitativos, são fundamentais. Além de se olhar criticamente para o discurso atual da inovação, que apresenta o protagonismo de tendências disseminadas sob a ótica de países que apresentam patamares econômicos e sociais já avançados e, por conseguinte, propícios ao processo inovativo.

\section{REFERÊNCIAS}

Aguirre-Bastos, C., \& Weber, M. K. (2018). Foresight for shaping national innovation systems in developing economies. Technological Forecasting and Social Change, 128, 186-196. Recuperado em 06 março, 2019, de https://www.sciencedirect.com/science/article/pii/S0040162517316736.

Albuquerque, E. D. M. (2009). Catching up no século XXI: construção combinada de sistemas de inovação e de bem-estar social. In J. Sicsú, \& P. Miranda (Org.). Crescimento econômico: estratégias e instituições (pp. 55-83). Rio de Janeiro: Ipea. 
Arend, M., \& Fonseca, P. C. D. (2012). Brasil (1955-2005): 25 anos de catching up, 25 anos de falling behind. Brazilian Journal of Political Economy, 32(1), 33-54.

Brasil. Presidência da República. Secretaria de Planejamento. (1973). Plano Básico de Desenvolvimento Científico e Tecnológico 1973/74. Rio de Janeiro: SERGRAF do IBGE.

Brasil. Presidência da República. Secretaria de Planejamento. (1976). Plano Básico de Desenvolvimento Científico e Tecnológico 1976/79. Rio de Janeiro: SERGRAF do IBGE.

Brasil. Presidência da República. Secretaria de Planejamento. (1980). Plano Básico de Desenvolvimento Científico e Tecnológico 1980/85. São Paulo: CNPq.

Bresser-Pereira, L. C. (2008). O conceito histórico de desenvolvimento econômico. Recuperado em: 11 abril, 2019, de

http://www.bresserpereira.org.br/papers/2008/08.18.ConceitoHist\%C3\%B3ricoDesenvolvimento.31.5.pdf.

Cassiolato, J. (2013). As políticas de ciência, tecnologia e inovação na China. Boletim de Economia e Política Internacional (pp. 65-80). Recuperado em: 05 julho, 2018, de

http://repositorio.ipea.gov.br/bitstream/11058/3928/1/BEPI_n13_politicas.pdf.

Cavalcante, L. R. (2010). Políticas de Ciência, Tecnologia e Inovação no Brasil: uma análise com base nos indicadores agregados [Texto para discussão No 1458]. Rio de Janeiro: Ipea.

Chang, H. J. (2004). Chutando a escada: a estratégia do desenvolvimento em perspectiva histórica. São Paulo: UNESP.

Filgueiras, F. (2009). A tolerância à corrupção no Brasil: uma antinomia entre normas morais e prática social. Opinião Publica, 15(2) 386-421. Recuperado em 08 julho, 2018, de http://www.scielo.br/scielo.php?script=sci_arttext\&pid=S010462762009000200005\&lng=en\&nrm=iso.

Freeman, C. (1988). Introduction. In: DOSI, G.; FREEMAN,C.; NELSON, R.; SILVERBERG, G.; SOETE, L. (org.). Technical change and economic theory (pp. 1-8). London: Pinter Publishers.

Freeman, C. (1989). Technology policy and economic performance (p. 34). Great Britain: Pinter Publishers.

Furtado, C. (1978). Criatividade e dependência na civilização industrial. Rio de Janeiro: Paz e Terra.

Furtado, C. (2009). Desenvolvimento e subdesenvolvimento. Rio de Janeiro: Contraponto.

Gala, P. (2017). Complexidade Econômica: uma nova perspectiva para entender a antiga questão da Riqueza das Nações. Rio de Janeiro: Contraponto.

Gaspar, R. C. (2015). A trajetória da economia mundial: da recuperação do pós-guerra aos desafios contemporâneos. Cadernos Metrópole, 17(33), 265-296. Recuperado em 11 abril, 2019, de http://www.scielo.br/pdf/cm/v17n33/2236-9996-cm-17-33-0265.pdf.

Global Innovation Index - Indicator Rankings \& Analysis (n.d.). Base de Dados [Online]. Recuperado em 26 julho, 2019, de https://www.globalinnovationindex.org/analysis-indicator.

Heeks, R., Amalia, M., Kintu, R., \& Shah, N. (2013). Inclusive innovation: definition, conceptualisation and future research priorities. IDPM Development Informatics Working Papers. Recuperado em 30 julho, 2019 de https://www.escholar.manchester.ac.uk/api/datastream?publicationPid=uk-ac-manscw:220238\&datastreamld=FULL-TEXT.PDF. 
Heeks, R., Foster, C., \& Nugroho, Y. (2014). New models of inclusive innovation for development. Recuperado e,m 30 julho, 2019 de https://www.tandfonline.com/doi/full/10.1080/2157930X.2014.928982.

Instituto Brasileiro de Geografia e Estatística (IBGE). (2016). Pesquisa Nacional por Amostra de Domicílios Contínua - PNAD Contínua: trabalho infantil. Rio de Janeiro. Recuperado em 09 setembro, 2018, de https://biblioteca.ibge.gov.br/visualizacao/livros/liv101388_informativo.pdf.

IBGE. (2017). Síntese de indicadores sociais: uma análise das condições de vida da população brasileira. Rio de Janeiro. Recuperado em 08 julho, 2018, de https://biblioteca.ibge.gov.br/index.php/bibliotecacatalogo?view=detalhes\&id=2101459.

Jones, R. S. \& Yoo, B. (2011). Korea's Green Growth Strategy: Mitigating Climate Change and Developing New Growth Engines. OECD Economics Department Working Papers. Recuperado em 02 julho, 2018, de https://www.oecd ilibrary.org/economics/korea-s-green-growth-strategy_5kmbhk4gh1ns-en.

Kaldor, N. (1957). Características do desenvolvimento econômico. Revista Brasileira de Economia, 11(1), 318. Recuperado em 04 abril, 2019, de http://bibliotecadigital.fgv.br/ojs/index.php/rbe/article/download/1870/2751.

Kuznets, S. S. (1985). Crescimento econômico moderno: descobertas e reflexões. Revista Brasileira de Economia, 39(2), 225-239. Recuperado em 23 junho, 2018, de http://bibliotecadigital.fgv.br/ojs/index.php/rbe/article/viewFile/8888/7753.

Lundvall, B.-Å. (1988). Innovation as an interactive process: from user-producer interaction to the national system innovation (pp. 349-369). In: Dosi, G.; Freeman,C.; Nelson, R.; Silverberg, G.; Soete, L. (org.). Technical change and economic theory. London: Pinter Publishers.

Lundvall, B.-Å (Org.). (1992). National Innovation Systems: Towards a Theory of Innovation and Interactive Learning. Londres: Pinter Publishers.

Manini, R. (2015). 30 anos do MCTI: Estabilidade e responsabilidade na política de inovação são principais marcas. Ciência e Cultura, 67(2), 8-9. Recuperado em 08 julho, 2018, de http://cienciaecultura.bvs.br/scielo.php?script=sci_arttext\&pid=S0009 $67252015000200003 \&$ Ing=en\&nrm=iso.

Marx, K. (2013). O capital: crítica da economia política: livro I: O processo de produção do capital: volume 1. 30 ed. São Paulo: Civilização Brasileira.

Mazzucato, M. (2014). O Estado Empreendedor: desmascarando o mito do setor público vs. setor privado (E. Serapicos, Trad.). São Paulo: Portfolio-Penguin.

Ministério da Indústria, Comércio Exterior e Serviços (MDIC). (2003). Diretrizes de Política Industrial, Tecnológica e de Comércio Exterior. Brasília. Recuperado em 02 julho, 2018, de http://www.abdi.com.br/Estudo/Diretrizes_PITCE.pdf.

MCDIC. (2011). Brasil Maior: Plano 2011 - 2014. Brasília: MDIC. Recuperado em 01 julho, 2018, de http://www.abdi.com.br/Estudo/Plano\%20Brasil\%20Maior\%20-\%20FINAL.pdf.

Ministério da Ciência e Tecnologia (MCT). (2010). Plano de Ação em Ciência, Tecnologia e Inovação: principais resultados e avanços: 2007 - 2010. Brasília. Recuperado em 02 julho, 2018, de http:/livroaberto.ibict.br/handle/1/676.

Ministério da Ciência, Tecnologia e Inovação (MCTI). (2012). Estratégia Nacional de Ciência, Tecnologia e Inovação 2012 - 2015. Brasília. Recuperado em 06 julho, 2018 de, http://ivroaberto.ibict.br/218981.pdf. 
Ministério da Ciência, Tecnologia, Inovações e Comunicações (MCTIC). (2016a). Estratégia

Nacional de Ciência, Tecnologia e Inovação 2016 - 2019. Brasília. Recuperado em 25 junho, 2018, de http://www.propesq.unir.br/uploads/76767676/arquivos/Estrat_gia_Nacional_de_Ci_ncia_T ecnologia_e_Inova_0_2016_2019_1248378469.pdf.

MCTIC. (2016b). Estratégia Nacional de Ciência, Tecnologia e Inovação 2016 - 2022. Brasília. Recuperado em 2 junho, 2018, de https://portal.insa.gov.br/images/documentos-oficiais/ENCTI-MCTIC-20162022.pdf.

MCTIC. (2017). Indicadores Nacionais de Ciência, Tecnologia Inovação. Brasilia: MCTIC. Recuperado em 06 julho, 2018, de http://www.mctic.gov.br/mctic/export/sites/institucional/indicadores/arquivos/Indicadores2017.pdf.

MCTIC. (n.d.). Institucional [Online]. Recuperado em 07 março, 2019, de http://www.mctic.gov.br/mctic/opencms/institucional/paginalnstitucional.html.

Meneghetti, F. K. (2011). O que é um ensaio-teórico?. Revista de Administração Contemporânea, 15(2), 320332. Recuperado em 07 março, 2018, de https://dx.doi.org/10.1590/\$1415-65552011000200010.

Nelson, R. R., Rosenberg, N. (1993). Technical Innovation and National System. In: Nelson, R. R. (Ed.). National innovation systems: a comparative analysis. Oxford University Press on Demand.

Nelson, R. R. (Ed.). (1993). National innovation systems: a comparative analysis. Oxford University Press on Demand.

Nelson, R. R. \& Winter, S. G. (1977). In search of a useful theory of innovation. In: Innovation, economic change and technology policies. Birkhäuser, Basel. Recuperado em 22 junho, 2018, de https://www.sciencedirect.com/science/article/pii/0048733377900294.

Organisation for Economic Co-operation and Development (OECD). (2015). Desigualdade e pobreza: Melhorando as políticas para reduzir a desigualdade e pobreza. Brazil Policy Brief. Recuperado em 08 julho, 2018, de https://www.oecd.org/policy-briefs/brasil-melhorando-aspoliticas-para-reduzir-adesigualdade-e-pobreza.pdf.

OECD. (2017). Education at a Glance 2017: Brazil. Recuperado em 07 julho, 2018, de https://www.oecdilibrary.org/education/education-at-a-glance-2017/brazil_eag-2017-74-en.

Organização das Nações Unidas (ONU). (n.d.). 17 Objetivos para transformar nosso mundo [Online]. Recuperado em 06 março, 2019, de https://nacoesunidas.org/pos2015/.

Pacheco, C. A. (2011). Uma comparação entre a agenda de inovação da China e do Brasil. São Paulo: IEDI. Recuperado em 07 julho, 2018, de

http://www.ipdeletron.org.br/wwwroot/pdfpublicacoes/15/Comparacao_entre_Agenda_Inovacao_China_B rasil.pdf.

Pivoto, D., Caruso, C. O., Niederle, P. A. (2016). Schumpeter e a teoria do desenvolvimento econômico. In: Niederle, P. A., Radomsky, G. F. W. Introdução às teorias do desenvolvimento. Porto Alegre: Editora da UFRGS.

Porter, M. E. (1990). The competitive advantage of nations (pp. 73-93). Cambridge: Harvard Business School Management Programs.

Prebisch, R. (1949). O desenvolvimento econômico da América Latina e seus principais problemas. Revista brasileira de economia, 3(3), pp. 47-111. 
Ricardo, D. (1996). Princípios de economia política e tributação. São Paulo: Editora Nova Cultural.

Rosenberg, N. (2006). Por dentro da caixa-preta: tecnologia e economia. Unicamp.

Schumpeter, J. A. (1961). Teoria do desenvolvimento econômico. Rio de Janeiro: Fundo de Cultura.

Schumpeter, J. A. (1962). Capitalism, socialism and democracy (3ª ed.). New York: Harper \& Row.

Schot, J., \& Steinmueller, W. E. (2018). Three frames for innovation policy: R\&D, systems of innovation and transformative change. Research Policy, 47(9), 1554-1567. Recuperado em 06 março, 2019, de https://www.sciencedirect.com/science/article/pii/S0048733318301987.

Siqueira, T. (2010). O trabalho escravo perdura no Brasil no século XXI. Revista do Tribunal Regional do Trabalho da $3^{a}$ Região, 52 (82), 127-147. Recuperado em 9 julho, 2018, de https://hdl.handle.net/20.500.12178/74434.

Smith, A. (1996). A riqueza das nações: investigação sobre sua natureza e suas causas (Vol. 1). São Paulo: Editora Nova Cultural Ltda.

Soares, D. de Queiroz. (2011). Inovação Tecnológica: Desafios e Perspectivas dos Países Subdesenvolvidos. Desigualdade \& Diversidade - Revista de Ciências Sociais da PUC-Rio, (8), 101-117. Recuperado em 22 maio, 2018, de http://desigualdadediversidade.soc.pucrio.br/media/artigo3_8.pdf.

Sunkel, O., Paz, P., \& Maia, J. (1976). A teoria do desenvolvimento econômico. São Paulo: Difel.

Turchi, L. M., \& Arcuri, M. (2017). Interação institutos públicos de pesquisa e empresas: avaliação das parcerias. In L. M. Turchi, \& J. M. Morais. Políticas de apoio à inovação tecnológica no Brasil: avanços recentes, limitações e propostas de ações (pp. 81-112). Brasília: Ipea.

Organização das Nações Unidas para a Educação, a Ciência e a Cultura. (2015). UNESCO Science Report: towards 2030 - Executive Summary. Paris. Recuperado em 22 maio, 2018, de unesdoc.unesco.org/images/0023/002354/235407e.pdf. 